O'Nions E, Wolke D, Johnson S, Kennedy E. Preterm birth: Educational and mental health outcomes. Clin Child Psychol Psychiatry. Copyright (C) 2021. DOI: 10.1177/13591045211006754

\title{
Preterm birth: Educational and mental health outcomes
}

Elizabeth O’Nions ${ }^{1,2}$, Dieter Wolke ${ }^{3,4}$, Samantha Johnson ${ }^{5}$ and Eilis Kennedy ${ }^{1,2}$

${ }^{1}$ Research and Development Unit, The Tavistock \& Portman NHS Foundation Trust, London, UK

${ }^{2}$ Research Department of Clinical, Educational, and Health Psychology, Division of Psychology and Language

Sciences, University College London, UK

${ }^{3}$ Division of Mental Health and Wellbeing, Warwick Medical School, Coventry, UK

${ }^{4}$ Department of Psychology, University of Warwick, Coventry, UK

${ }^{5}$ Department of Health Sciences, University of Leicester, UK

\section{Corresponding author:}

Elizabeth O’Nions, Research and Development Unit, The Tavistock \& Portman NHS Foundation Trust, 120

Belsize Lane, London NW3 5BA, UK.

Email: e.onions@ucl.ac.uk

\section{Declaration of conflicting interests:}

The author(s) declared no potential conflicts of interest with respect to the research, authorship, and/or publication of this article.

\section{Funding:}

The author(s) disclosed receipt of the following financial support for the research, authorship, and/or publication of this article: DW and SJ were partly supported by funding from the European Union's Horizon 2020 Research and Innovation Programme RECAP-Preterm project (grant no. 733280). DW received additional support from the NORFACE DIAL programme (grant no. 462-16-040).

\section{Introduction}


O'Nions E, Wolke D, Johnson S, Kennedy E. Preterm birth: Educational and mental health outcomes. Clin Child Psychol Psychiatry. Copyright (C) 2021. DOI: 10.1177/13591045211006754

Preterm birth (birth at less than 37 weeks' gestation) is common and represents a major contributor to global child morbidity and mortality. An estimated $10.6 \%$ of live births, nearly 15 million births annually, occur before 37 completed weeks of gestation (Chawanpaiboon et al., 2019). Collectively, 'extremely' preterm births (births at $<28$ weeks) and 'very' preterm births (births at 28-31 weeks) make up around $15 \%$ of all preterm births, whilst 'moderate to late' preterm births (births at 32- 36 weeks) make up the vast majority (85\%)

(Chawanpaiboon et al., 2019). In high income settings, advances in neonatal care during the last 30 years mean that the number of people growing up as survivors of preterm birth is increasing (Smith et al., 2014; Zeitlin et al., 2016). This has led to increased interest in their long-term outcomes.

Findings consistently indicate that on average, children born preterm experience poorer mental health and educational outcomes compared to their term-born peers (Allotey et al., 2018; Bhutta et al., 2002; MacKay et al., 2010; Pettinger et al., 2019; Poulsen et al., 2013; World Health Organization [WHO], 2020; Wolke et al., 2019). The likelihood of experiencing difficulties is inversely related to gestational age at birth, with those born extremely preterm most affected (e.g., Chan \& Quigley, 2014; Quigley et al., 2012). Although the majority of those who graduate from neonatal units after very or extremely preterm birth do not have neurodevelopmental impairments (Wolke et al., 2019), subthreshold difficulties are more prevalent. Preterm birth accounts for around $3.6 \%$ of population attributable fraction of special educational needs (MacKay et al., 2010).

Preterm birth is associated with lower scores on IQ tests. Children and adolescents born very preterm or at a very low birth-weight $(<1,500 \mathrm{~g})$ score, on average, 12.9 IQ points below term-born controls (Twilhaar et al., 2018 b). Those born at $<26$ weeks, at the most extremely preterm gestations, score an average of 20 IQ points below those born at term (Johnson et al., 2009). Executive functioning difficulties, including modest deficits in processing speed, verbal fluency, cognitive flexibility and working memory may underlie poorer performance in cognitive assessments and academic outcomes (Aarnoudse-Moens et al., 2009; Allotey et al., 2018; Brydges et al., 2018).

Cognitive outcomes for children born preterm appear to be stable: they do not seem to catch-up with term-born peers as they grow up (Breeman et al., 2015; Eryigit Madzwamuse et al., 2015; Linsell et al., 2018). Furthermore, those born very preterm into socially disadvantaged families experience a long term 'double jeopardy' with IQ scores much lower than those born into more socially advantaged families (BenaventeFernández et al., 2019; Eryigit Madzwamuse et al., 2015; Wolke, 2019).

In terms of educational outcomes, preterm-born children have an increased likelihood of experiencing difficulties in all areas of the curriculum, but especially in mathematics (Jaekel \& Wolke, 2014; Johnson et al., 2011; Wolke et al., 2019). Mathematics difficulties have been linked to problems with working memory and visuo-spatial skills rather than to poor numerical skills (Simms et al., 2015). Like cognitive outcomes, academic difficulties experienced by preterm-born children appear to be stable throughout primary school (Twilhaar et al., 2018a).

Preterm birth also increases the likelihood of neurodevelopmental and certain mental health difficulties.

Children born very preterm have, on average, poorer attention and more social-communication difficulties, peer 
O'Nions E, Wolke D, Johnson S, Kennedy E. Preterm birth: Educational and mental health outcomes. Clin Child Psychol Psychiatry. Copyright (C) 2021. DOI: 10.1177/13591045211006754

problems, and internalising symptoms than their term-born peers (Arpi \& Ferrari, 2013; Johnson \& Marlow, 2011; Johnson \& Wolke, 2013; Ritchie et al., 2015). They are also significantly more likely to be diagnosed with ADHD (Breeman et al., 2016; Franz et al., 2018; Halmøy et al., 2012; Johnson et al., 2010b), autism spectrum disorder (Agrawal et al., 2018; Johnson et al., 2010a, 2010b) and anxiety disorder (Johnson et al., 2010 b) compared to term-born children, but do not show increased rates of conduct or impulse-control disorders (Johnson \& Marlow, 2011; Johnson \& Wolke, 2013).

Links between preterm birth and depression during childhood are less clear. A recent population register study based on births between 1987 and 2007 reported increased rates of diagnosed depression in girls born extremely preterm at less than 28 weeks, but not boys (Upadhyaya et al., 2020). There was no link between very or moderate to late preterm births and depression during childhood in either sex (Upadhyaya et al., 2020). An increase in the likelihood of depression at age 11 was also seen in the EPICure cohort study of births $<26$ weeks, which reported that $9 \%$ of preterm, but only $2 \%$ of controls, had emotional disorders (Johnson et al., 2010b).

Considering adult psychiatric illness, work in a Swedish register study suggests links between preterm birth and psychiatric disorders and the likelihood of receiving psychiatric treatment (Crump et al., 2010; Moster et al., 2009; Nosarti et al., 2012). However, these findings may be partly attributable to environmental confounding, given that factors such as socio-economic deprivation, maternal stress, and smoking during pregnancy may increase the likelihood of both preterm birth and later psychiatric hospitalisation. These factors may not be routinely measured and therefore cannot be adjusted for when register data are analysed. A further consideration is that greater contact with health services among preterm-born individuals may lead to greater detection of mental ill-health and prescriptions of psychopharmica.

Cohort studies provide a counterpoint to register studies in that they assess preterm and term-born comparison individuals using the same measures, and can include measures of possible confounders. Cohort studies can assess factors contributing to mental health such as parenting and peer experiences including bullying or romantic relationships (Heuser et al., 2018; Jaekel et al., 2018), which are not covered in register studies. Cohort studies thus reduce the likelihood that differential detection of mental health problems or environmental confounders inflate associations between preterm birth and poorer outcomes, and can also be used to investigate developmental mechanisms.

Intriguingly, cohort study data for young adults born at extremely low birth-weights $(<1,000 \mathrm{~g})$ does not suggest an increased risk of psychiatric diagnoses in extremely low birth-weight children compared to matched normal birth-weight controls (Van Lieshout et al., 2018). Follow-up in both the Bavarian Longitudinal Study of babies born very preterm at $<1,500 \mathrm{~g}$, and in the EPICure cohort study of births at $<26$ weeks also found no increased risk of depression in adulthood compared to matched controls, although the EPICure data did suggest an increase in depression symptoms (Jaekel et al., 2018; Johnson et al., 2019c). Adults who were born very preterm also self-report more internalising symptoms compared to term-born adults (Pyhälä et al., 2017).

Preterm birth, brain development, and early care 
O'Nions E, Wolke D, Johnson S, Kennedy E. Preterm birth: Educational and mental health outcomes. Clin Child Psychol Psychiatry. Copyright (C) 2021. DOI: 10.1177/13591045211006754

For individuals born preterm, brain maturation outside of the uterine milieu, common medical complications, plus separation from parents due to hospitalisation may contribute to lasting changes in brain and autonomic development. The period between the current threshold of viability ( $22-24$ weeks) and term (40 weeks) is a stage when the brain is developing rapidly. A four-fold increase in cortical volume occurs between 28 and 40 weeks' gestation (Volpe, 2009), which, in infants born preterm, occurs in an atypical extra-uterine biological milieu. This leads to alterations in cortical development, resulting in what has been described as the 'building of a different brain' compared to babies born at term (Wolke et al., 2019, p. 82).

Cross-sectional studies comparing preterm and term-born individuals suggest that the impact of preterm birth on brain development persists into adulthood. Studies have identified structural differences, including reduced cortical gyrification (Papini et al., 2020) and alterations in network connectivity (Bäuml et al., 2015; Karolis et al., 2016) in children and adults born preterm, plus changes in the trajectory of cerebral development from latechildhood to early adolescence (Ment et al., 2009) and still seen in adulthood (Hedderich et al., 2020). Volumetric changes in regions implicated in socio-emotional processing are also evident (see Montagna \& Nosarti, 2016).

Infants born very or extremely preterm in high income settings often spend several weeks or months in a neonatal intensive care unit (NICU). During NICU care, infants are frequently exposed to unavoidable invasive and painful procedures, which have been linked to alterations in hypothalamic-pituitary-adrenal (HPA) functioning (Brummelte et al., 2015; Eckstein Grunau, 2013). They also experience tactile deprivation due to incubator care and separation from their parents. Encouragingly, daily skin-to-skin 'kangaroo' care, during which the infant is placed unclothed on the mother's (or father's) chest, improves child autonomic and circadian development, maternal attachment behaviour, and mother-infant synchrony compared to standard incubator care (Feldman et al., 2014; Feldman \& Eidelman, 2003). At age 10, babies who received kangaroo care show better resilience to social and emotional stress, better sleep organisation and better executive functioning compared to incubator care controls (Feldman et al., 2014).

Facilitating parental presence in the NICU may therefore promote better long-term outcomes for preterm babies. Rates of infant mortality, serious medical complications and poorer cognitive functioning are lower in infants cared for in NICUs with access to single family rooms, in which parents can stay with their child 24 hours per day (Lehtonen et al., 2020; Vohr et al., 2017). This alleviates parental anxiety and distress at separation, and allows parents to play more of a role in their infant's care, potentially including extended periods of 'Kangaroo care. Unfortunately, most neonatal units in high-income countries currently lack facilities to support parents' presence 24 hours per day (Lehtonen et al., 2020).

The recent COVID-19 pandemic has resulted in limitations on parental access to NICUs in many hospital settings (e.g., Muniraman et al., 2020). This has reduced opportunities for parents to bond with their babies and care for them whilst in hospital. The potential adverse consequences of lack of parental contact for infant development have led to a campaign run by the Global Alliance for Newborn Care, a global initiative of the 
O'Nions E, Wolke D, Johnson S, Kennedy E. Preterm birth: Educational and mental health outcomes. Clin Child Psychol Psychiatry. Copyright (C) 2021. DOI: 10.1177/13591045211006754

European Foundation for the Care of Newborn Infants, to ensure that unrestricted parental access to neonatal units is protected (Global Alliance for Newborn Care, 2020).

\section{Psychosocial development across the lifespan and preterm birth}

Psychosocial factors, from socioeconomic status to parenting, peer relationships, and bullying victimisation have a significant impact on long-term outcomes for preterm-born children. Parental sensitivity appears to be a key factor linked to positive developmental outcomes. In general, mothers of preterm babies appear to be remarkably resilient and similarly sensitive towards their infants compared to mothers of term-born babies (Bilgin \& Wolke, 2015). However, for some parents and in some contexts, the stresses of preterm birth coupled with other factors impact them in such a way that their capacity to sensitively respond to their baby is reduced (Hall et al., 2017). This may in turn impact child outcomes: among very preterm babies exposed to more skinbreaking procedures in the NICU, higher parental sensitivity has been linked to lower levels of internalising behaviours at 18 months (Vinall et al., 2013). Responsive and involved parenting of babies in the NICU has also been linked to higher IQ scores in adults born very preterm (Jaekel et al., 2017).

Children born preterm appear to be particularly susceptible to certain forms of psychosocial adversity (Wolke, 2018; Wolke et al., 2019). The detrimental impact of low parental sensitivity appears to be greater in preterm compared to term-born children (Jaekel et al., 2015; Wolke et al., 2013). Cohort study data also suggest that adults born extremely preterm are more susceptible than term born adults to mental health problems when they have experienced psychosocial adversity (e.g. family dysfunction, peer victimisation, child abuse) (Van Lieshout et al., 2018).

As well as differences in sensitivity to adversity, preterm birth may also be linked to differences in the likelihood of exposure to adversity. Children born very or extremely preterm are at least three times as likely to be chronically bullied ( $\geqslant$ two times per week) during childhood compared to their term-born counterparts $(12 \%$ $14 \%$ vs $4 \%$ for term-born peers; Ritchie et al., 2018). Bullying victimisation acts as a mediator of internalising symptoms in childhood and psychotic symptoms in young adulthood (Liu et al., 2021; Wolke et al., 2015).

Environmental mediation of risk and resilience opens up the possibility of intervening to either prevent or promote active management of risk factors and thus improve wellbeing for children born preterm (Wolke, 2018). Interventions that aim to improve cognitive/motor outcomes or parent-infant interaction beginning during infancy appear to offer modest benefits up to preschool age (Spittle et al., 2015). Beyond structured interventions, a wider range of approaches may offer long-term benefits. This could include extended periods of skin-to-skin care whilst in the NICU, better support for parents' emotional health post-discharge, and support to develop peer relationships in childhood and adolescence.

Work is needed to identify mechanisms by which vulnerabilities related to preterm birth can, under certain conditions, lead to poorer functioning. Difficulties with working memory in preterm-born children may lead to problems with mental arithmetic, and deficits across a range of executive functions have been shown to mediate the relationship between preterm birth and attainment at school (Eves et al., 2020). Cognitive and learning 
O'Nions E, Wolke D, Johnson S, Kennedy E. Preterm birth: Educational and mental health outcomes. Clin Child Psychol Psychiatry. Copyright (C) 2021. DOI: 10.1177/13591045211006754

difficulties may form part of a cascade leading to poorer educational outcomes (Pettinger et al., 2019).

Therefore, there is an imperative to upskill educational professionals in relation to understanding the impact of preterm birth and identifying how to better support children who experience difficulties. Resources such as those developed by Johnson and colleagues (www.pretermbirth.info; Johnson et al., 2019b) have been used to raise awareness of prematurity amongst teachers, and offer specific guidance on strategies to support pupils with the cognitive and social-emotional difficulties most commonly associated with preterm birth (Johnson et al., 2019a).

At present, the main focus of care for preterm babies in the UK is the neonatal period, reflecting a lack of widespread recognition of the lasting neuro-behavioural, cognitive, and mental health impact of preterm birth. In the UK, the National Institute for Health and Care Excellence (NICE) guideline developed in 2017 recommends developmental follow up to age 2 years for children born at 30 weeks' gestation or earlier, or at 30 to 36 weeks where there are additional risk factors for developmental problems and disorders (NICE guideline, 2017). Further follow-up at age 4 is recommended for those born before 28 weeks (NICE guideline, 2017). This means that, in the UK, most preterm-born children do not receive any follow-up additional to universal screening offered via the Healthy Child Programme, and opportunities for timely support may be missed.

Preterm birth has a lasting impact on child educational and mental health outcomes. Parent-led organisations have started advocating for greater recognition of and research into the ongoing impact of preterm birth (Marlow et al., 2020; Ogilvy et al., 2017). Adults born preterm report that health professionals beyond those involved in early-life care are often unaware of their health needs, highlighting the need for better education on preterm birth for health professionals working with adolescents and adults (Perez et al., 2020). Considerably more work is needed to identify fruitful interventions or support strategies to ensure that preterm-born children achieve their potential. Affecting nearly 15 million children born annually worldwide, preterm birth deserves more attention as a significant and potentially modifiable risk factor for poorer educational and mental health outcomes.

\section{References}

Aarnoudse-Moens, C. S. H., Smidts, D. P., Oosterlaan, J., Duivenvoorden, H. J., \& Weisglas-Kuperus, N. (2009). Executive function in very preterm children at early school age. Journal of Abnormal Child Psychology, 37(7), 981-993. https://doi.org/10.1007/s10802-009-9327-z

Agrawal, S., Rao, S. C., Bulsara, M. K., \& Patole, S. K. (2018). Prevalence of autism spectrum disorder in preterm infants: A meta-analysis. Pediatrics, 142(3), e20180134. https://doi.org/10.1542/peds.20180134

Allotey, J., Zamora, J., Cheong-See, F., Kalidindi, M., Arroyo-Manzano, D., Asztalos, E., van der Post, J., Mol, B., Moore, D., Birtles, D., Khan, K., \& Thangaratinam, S. (2018). Cognitive, motor, behavioural and academic performances of children born preterm: A meta-analysis and systematic review involving 64 061 children. BJOG: An International Journal of Obstetrics \& Gynaecology, 125(1), 16-25. https:// doi.org/10.1111/1471-0528.14832 
O'Nions E, Wolke D, Johnson S, Kennedy E. Preterm birth: Educational and mental health outcomes. Clin Child Psychol Psychiatry. Copyright (C) 2021. DOI: 10.1177/13591045211006754

Arpi, E., \& Ferrari, F. (2013). Preterm birth and behaviour problems in infants and preschool-age children: A review of the recent literature. Developmental Medicine \& Child Neurology, 55(9), 788-796. https:// doi.org/10.1111/dmcn.12142

Bäuml, J. G., Daamen, M., Meng, C., Neitzel, J., Scheef, L., Jaekel, J., Busch, B., Baumann, N., Bartmann, P., Wolke, D., Boecker, H., Wohlschläger, A. M., \& Sorg, C. (2015). Correspondence between aberrant intrinsic network connectivity and gray-matter volume in the ventral brain of preterm born adults. Cerebral Cortex, 25(11), 4135-4145. https://doi.org/10.1093/cercor/bhu133

Benavente-Fernández, I., Synnes, A., Grunau, R. E., Chau, V., Ramraj, C., Glass, T., Cayam-Rand, D., Siddiqi, A., \& Miller, S. P. (2019). Association of socioeconomic status and brain injury with neurodevelopmental outcomes of very preterm children. JAMA Network Open, 2(5), e192914. https://doi. org/10.1001/jamanetworkopen.2019.2914

Bhutta, A. T., Cleves, M. A., Casey, P. H., Cradock, M. M., \& Anand, K. J. S. (2002). Cognitive and behavioral outcomes of school-aged children who were born preterm. JAMA, 288(6), 728. https://doi.org/10.1001/ jama.288.6.728

Bilgin, A., \& Wolke, D. (2015). Maternal sensitivity in parenting preterm children : A meta-analysis. Pediatrics, 136(1), e177-e193. https://doi.org/10.1542/peds.2014-3570

Breeman, L. D., Jaekel, J., Baumann, N., Bartmann, P., \& Wolke, D. (2015). Preterm cognitive function into adulthood. Pediatrics, 136(3), 415-423. https://doi.org/10.1542/peds.2015-0608

Breeman, L. D., Jaekel, J., Baumann, N., Bartmann, P., \& Wolke, D. (2016). Attention problems in very preterm children from childhood to adulthood : The Bavarian longitudinal study. Journal of Child Psychology and Psychiatry, 2, 132-140. https://doi.org/10.1111/jcpp.12456

Brummelte, S., Chau, C. M. Y., Cepeda, I. L., Degenhardt, A., Weinberg, J., Synnes, A. R., \& Grunau, R. E. (2015). Cortisol levels in former preterm children at school age are predicted by neonatal procedural pain- related stress. Psychoneuroendocrinology, 51, 151-163. https://doi.org/10.1016/j.psyneuen.2014.09.018

Brydges, C. R., French, N., Landes, J. K., Reid, C. L., Campbell, C., \& Anderson, M. (2018). Cognitive outcomes in children and adolescents born very preterm: A meta-analysis. Developmental Medicine \& Child Neurology, 60(5), 452-468. https://doi.org/10.1111/dmcn.13685

Chan, E., \& Quigley, M. A. (2014). School performance at age 7 years in late preterm and early term birth: A cohort study. Archives of Disease in Childhood - Fetal and Neonatal Edition, 99(6), F451-F457. https:// doi.org/10.1136/archdischild-2014-306124

Chawanpaiboon, S., Vogel, J. P., Moller, A.-B., Lumbiganon, P., Petzold, M., Hogan, D., Landoulsi, S., Jampathong, N., Kongwattanakul, K., Laopaiboon, M., Lewis, C., Rattanakanokchai, S., Teng, D. N., Thinkhamrop, J., Watananirun, K., Zhang, J., Zhou, W., \& Gülmezoglu, A. M. (2019). Global, regional, and national estimates of levels of preterm birth in 2014: A systematic review and modelling analysis. The Lancet Global Health, 7(1), e37-e46. https://doi.org/10.1016/S2214-109X(18)30451-0 
O'Nions E, Wolke D, Johnson S, Kennedy E. Preterm birth: Educational and mental health outcomes. Clin Child Psychol Psychiatry. Copyright (C) 2021. DOI: 10.1177/13591045211006754

Crump, C., Winkleby, M. A., Sundquist, K., \& Sundquist, J. (2010). Preterm birth and psychiatric medication prescription in young adulthood: A Swedish national cohort study. International Journal of Epidemiology, 39(6), 1522-1530. https://doi.org/10.1093/ije/dyq103

Eckstein Grunau, R. (2013). Neonatal pain in very preterm infants: Long-term effects on brain, neurodevelopment and pain reactivity. Rambam Maimonides Medical Journal, 4(4). https://doi.org/10.5041/ RMMJ.10132

Eryigit Madzwamuse, S., Baumann, N., Jaekel, J., Bartmann, P., \& Wolke, D. (2015). Neuro-cognitive performance of very preterm or very low birth weight adults at 26 years. Journal of Child Psychology and Psychiatry, 56(8), 857-864. https://doi.org/10.1111/jcpp.12358

Eves, R., von Mühlenen, A., Mendonça, M., Johnson, S., O’Reilly, H., Bartmann, P., Marlow, N., \& Wolke, D. (2020). The role of executive and general cognitive functioning in the attention problems of very and extremely preterm adults. Journal of Developmental \& Behavioral Pediatrics, 41(6), 461-469. https:// doi.org/10.1097/DBP.0000000000000806

Feldman, R., \& Eidelman, A. I. (2003). Skin-to-skin contact (Kangaroo Care) accelerates autonomic and neurobehavioural maturation in preterm infants. Developmental Medicine \& Child Neurology, 45(04). https://doi.org/10.1017/S0012162203000525

Feldman, R., Rosenthal, Z., \& Eidelman, A. I. (2014). Maternal-preterm skin-to-skin contact enhances child physiologic organization and cognitive control across the first 10 years of life. Biological Psychiatry, 75(1), 56-64. https://doi.org/10.1016/j.biopsych.2013.08.012

Franz, A. P., Bolat, G. U., Bolat, H., Matijasevich, A., Santos, I. S., Silveira, R. C., Procianoy, R. S., Rohde, L. A., \& Moreira-Maia, C. R. (2018). Attention-deficit/hyperactivity disorder and very preterm/very low birth weight: A meta-analysis. Pediatrics, 141(1), e20171645. https://doi.org/10.1542/peds.2017-1645

Global Alliance for Newborn Care. (2020). Zero separation. Together for better care! campaign press release. https://www.glance-network.org/wp-content/uploads/News/2020_Press_Release_Zero_seperation_after_Embargo.pdf

Hall, R. A. S., Hoffenkamp, H. N., Braeken, J., Tooten, A., Vingerhoets, A. J. J. M., \& van Bakel, H. J. A. (2017). Maternal psychological distress after preterm birth: Disruptive or adaptive? Infant Behavior and Development, 49, 272-280. https://doi.org/10.1016/j.infbeh.2017.09.012

Halmøy, A., Klungsøyr, K., Skjærven, R., \& Haavik, J. (2012). Pre- and perinatal risk factors in adults with attention-deficit/hyperactivity disorder. Biological Psychiatry, 71(5), 474-481. https://doi.org/10.1016/j. biopsych.2011.11.013

Hedderich, D. M., Bäuml, J. G., Menegaux, A., Avram, M., Daamen, M., Zimmer, C., Bartmann, P., Scheef, L., Boecker, H., Wolke, D., Gaser, C., \& Sorg, C. (2020). An analysis of MRI derived cortical complexity in premature-born adults: Regional patterns, risk factors, and potential significance. NeuroImage, 208, 116438. https://doi.org/10.1016/j.neuroimage.2019.116438 
O'Nions E, Wolke D, Johnson S, Kennedy E. Preterm birth: Educational and mental health outcomes. Clin Child Psychol Psychiatry. Copyright (C) 2021. DOI: 10.1177/13591045211006754

Heuser, K. M., Jaekel, J., \& Wolke, D. (2018). Origins and predictors of friendships in 6- to 8-year-old children born at neonatal risk. The Journal of Pediatrics, 193, 93-101.e5. https://doi.org/10.1016/j. jpeds.2017.09.072

Jaekel, J., Baumann, N., Bartmann, P., \& Wolke, D. (2018). Mood and anxiety disorders in very preterm/very low-birth weight individuals from 6 to 26 years. Journal of Child Psychology and Psychiatry, 59(1), 8895. https://doi.org/10.1111/jcpp.12787

Jaekel, J., Baumann, N., Bartmann, P., Wolke, D., Breeman, L. D., Jaekel, J., Baumann, N., Bartmann, P., \& Wolke, D. (2017). Neonatal predictors of cognitive ability in adults born very preterm: A prospective cohort study. Developmental Medicine \& Child Neurology, 59(5), 477-483. https://doi.org/10.1111/ dmen. 13380

Jaekel, J., Pluess, M., Belsky, J., \& Wolke, D. (2015). Effects of maternal sensitivity on low birth weight children's academic achievement: A test of differential susceptibility versus diathesis stress. Journal of Child Psychology and Psychiatry, 56(6), 693-701. https://doi.org/10.1111/jcpp.12331

Jaekel, J., \& Wolke, D. (2014). Preterm birth and dyscalculia. The Journal of Pediatrics, 164(6), 1327-1332. https://doi.org/10.1016/j.jpeds.2014.01.069

Johnson, S., Bamber, D., Bountziouka, V., Clayton, S., Cragg, L., Gilmore, C., Griffiths, R., Marlow, N., Simms, V., \& Wharrad, H. J. (2019a). Improving developmental and educational support for children born preterm: Evaluation of an e-learning resource for education professionals. BMJ Open, $9(6)$, e029720. https://doi.org/10.1136/bmjopen-2019-029720

Johnson, S., Clayton, S., Cragg, L., Gilmore, C., Griffiths, R., Marlow, N., Simms, V., \& Wharrad, H. (2019b). Preterm Birth Information for Education Professionals. https://www.nottingham.ac.uk/helm/dev/prism/

Johnson, S., Fawke, J., Hennessy, E., Rowell, V., Thomas, S., Wolke, D., \& Marlow, N. (2009). Neurodevelopmental disability through 11 years of age in children born before 26 weeks of gestation. Pediatrics, 124(2), e249-e257. https://doi.org/10.1542/peds.2008-3743

Johnson, S., Hollis, C., Kochhar, P., Hennessy, E., Wolke, D., \& Marlow, N. (2010a). Autism spectrum disorders in extremely preterm children. The Journal of Pediatrics, 156(4), 525-531.e2. https://doi. org/10.1016/j.jpeds.2009.10.041

Johnson, S., Hollis, C., Kochhar, P., Hennessy, E., Wolke, D., \& Marlow, N. (2010b). Psychiatric disorders in extremely preterm children. Journal of the American Academy of Child \& Adolescent Psychiatry, 49(5), 453-463e1. https://doi.org/10.1097/00004583-201005000-00006

Johnson, S., \& Marlow, N. (2011). Preterm birth and childhood psychiatric disorders. Pediatric Research, 69(5 Part 2), 11R-18R. https://doi.org/10.1203/PDR.0b013e318212faa0

Johnson, S., O’Reilly, H., Ni, Y., Wolke, D., \& Marlow, N. (2019c). Psychiatric symptoms and disorders in extremely preterm young adults at 19 years of age and longitudinal findings from middle childhood. Journal of the American Academy of Child \& Adolescent Psychiatry, 58(8), 820-826.e6. https://doi. org/10.1016/j.jaac.2019.02.020 
O'Nions E, Wolke D, Johnson S, Kennedy E. Preterm birth: Educational and mental health outcomes. Clin Child Psychol Psychiatry. Copyright (C) 2021. DOI: 10.1177/13591045211006754

Johnson, S., \& Wolke, D. (2013). Early human development behavioural outcomes and psychopathology during adolescence. Early Human Development, 89(4), 199-207. https://doi.org/10.1016/j.earlhumdev.2013.01.014

Johnson, S., Wolke, D., Hennessy, E., \& Marlow, N. (2011). Educational outcomes in extremely preterm children: Neuropsychological correlates and predictors of attainment. Developmental Neuropsychology, 36(1), 74-95. https://doi.org/10.1080/87565641.2011.540541

Karolis, V. R., Froudist-Walsh, S., Brittain, P. J., Kroll, J., Ball, G., Edwards, A. D., Dell'Acqua, F., Williams, S. C., Murray, R. M., \& Nosarti, C. (2016). Reinforcement of the brain's rich-club architecture following early neurodevelopmental disruption caused by very preterm birth. Cerebral Cortex, 26(3), 1322-1335. https://doi.org/10.1093/cercor/bhv305

Lehtonen, L., Lee, S. K., Kusuda, S., Lui, K., Norman, M., Bassler, D., Håkansson, S., Vento, M., Darlow, B. A., Adams, M., Puglia, M., Isayama, T., Noguchi, A., Morisaki, N., Helenius, K., Reichman, B., \& Shah, P. S. (2020). Family rooms in NICUs and neonatal outcomes: An international survey and linked cohort study. The Journal of Pediatrics. Advance online publication. https://doi.org/10.1016/j. jpeds.2020.06.009

Linsell, L., Johnson, S., Wolke, D., O’Reilly, H., Morris, J. K., Kurinczuk, J. J., \& Marlow, N. (2018). Cognitive trajectories from infancy to early adulthood following birth before 26 weeks of gestation: A prospective, population-based cohort study. Archives of Disease in Childhood, 103(4), 363-370. https:// doi.org/10.1136/archdischild-2017-313414

Liu, Y., Mendonça, M., Johnson, S., O’Reilly, H., Bartmann, P., Marlow, N., \& Wolke, D. (2021). Testing the neurodevelopmental, trauma and developmental risk factor models of psychosis using a naturalistic experiment. Psychological Medicine, 51(3), 460-469. https://doi.org/10.1017/S0033291719003349

MacKay, D. F., Smith, G. C. S., Dobbie, R., \& Pell, J. P. (2010). Gestational age at delivery and special educational need: Retrospective cohort study of 407,503 schoolchildren. PLoS Medicine, 7(6), e1000289. https://doi.org/10.1371/journal.pmed.1000289

Marlow, N., Hoy, S., Peacock, A., \& Kamphuis, J. (2020). Outcomes from the other side. Seminars in Fetal and Neonatal Medicine, 25(3), 101125. https://doi.org/10.1016/j.siny.2020.101125

Ment, L. R., Kesler, S., Vohr, B., Katz, K. H., Baumgartner, H., Schneider, K. C., Delancy, S., Silbereis, J., Duncan, C. C., Constable, R. T., Makuch, R. W., \& Reiss, A. L. (2009). Longitudinal brain volume changes in preterm and term control subjects during late childhood and adolescence. Pediatrics, 123(2), 503-511. https://doi.org/10.1542/peds.2008-0025

Montagna, A., \& Nosarti, C. (2016). Socio-emotional development following very preterm birth: Pathways to psychopathology. Frontiers in Psychology, 7, 80. https://doi.org/10.3389/fpsyg.2016.00080

Moster, D., Lie, R. T., \& Markestad, T. (2009). Long-term medical and social consequences of preterm birth. Obstetric Anesthesia Digest, 29(2), 68-69. https://doi.org/10.1097/01.aoa.0000350603.68744.9e 
O'Nions E, Wolke D, Johnson S, Kennedy E. Preterm birth: Educational and mental health outcomes. Clin Child Psychol Psychiatry. Copyright (C) 2021. DOI: 10.1177/13591045211006754

Muniraman, H., Ali, M., Cawley, P., Hillyer, J., Heathcote, A., Ponnusamy, V., Coleman, Z., Hammonds, K., Raiyani, C., Gait-Carr, E., Myers, S., Hunt, K., Govande, V., Jain, A., Clark, R., Doherty, C., Raju, V., \& Clarke, P. (2020). Parental perceptions of the impact of neonatal unit visitation policies during COVID19 pandemic. BMJ Paediatrics Open, 4(1), e000899. https://doi.org/10.1136/bmjpo-2020-000899

NICE guideline. (2017). Developmental follow-up of children and young people born preterm. https://www. nice.org.uk/guidance/qs169/resources/developmental-followup-of-children-and-young-people-bornpreterm-pdf-75545608839109

Nosarti, C., Reichenberg, A., Murray, R. M., Cnattingius, S., Lambe, M. P., Yin, L., MacCabe, J., Rifkin, L., \& Hultman, C. M. (2012). Preterm birth and psychiatric disorders in young adult life. Archives of General Psychiatry, 69(6), E1-E8. https://doi.org/10.1001/archgenpsychiatry.2011.1374

Ogilvy, C., Miles, S., \& Hird, M. (2017). The smallest things life after neonatal care 2017 report. https://static1. squarespace.com/static/5da087447ccbad5c20ff9233/t/5dcf035d6ad93f5f5f2347fb/1573847906764/ lifeafter-nicu-report-2017.pdf

Papini, C., Palaniyappan, L., Kroll, J., Froudist-Walsh, S., Murray, R. M., \& Nosarti, C. (2020). Altered cortical gyrification in adults who were born very preterm and its associations with cognition and mental health. Biological Psychiatry: Cognitive Neuroscience and Neuroimaging, 5(7), 640-650 https://doi. org/10.1016/j.bpsc.2020.01.006

Perez, A., Thiede, L., Lüdecke, D., Ebenebe, C. U., von dem Knesebeck, O., \& Singer, D. (2020). Lost in transition: Health care experiences of adults born very preterm - a qualitative approach. Frontiers in Public Health, 8, 605149. https://doi.org/10.3389/fpubh.2020.605149

Pettinger, K. J., Kelly, B., Sheldon, T. A., Mon-Williams, M., Wright, J., \& Hill, L. J. B. (2019). Starting school: Educational development as a function of age of entry and prematurity. Archives of Disease in Childhood, 105, 160-165. https://doi.org/10.1136/archdischild-2019-317124

Poulsen, G., Wolke, D., Kurinczuk, J. J., Boyle, E. M., Field, D., Alfirevic, Z., \& Quigley, M. A. (2013). Gestational age and cognitive ability in early childhood: A population-based cohort study. Paediatric and Perinatal Epidemiology, 27(4), 371-379. https://doi.org/10.1111/ppe.12058

Pyhälä, R., Wolford, E., Kautiainen, H., Andersson, S., Bartmann, P., Baumann, N., Brubakk, A.-M., Evensen, K. A. I., Hovi, P., Kajantie, E., Lahti, M., Van Lieshout, R. J., Saigal, S., Schmidt, L. A., Indredavik, M. S., Wolke, D., \& Räikkönen, K. (2017). Self-reported mental health problems among adults born preterm: A meta-analysis. Pediatrics, 139(4), e20162690. https://doi.org/10.1542/peds.2016-2690

Quigley, M. A., Poulsen, G., Boyle, E., Wolke, D., Field, D., Alfirevic, Z., \& Kurinczuk, J. J. (2012). Early term and late preterm birth are associated with poorer school performance at age 5 years: A cohort study. Archives of Disease in Childhood - Fetal and Neonatal Edition, 97(3), F167-F173. https://doi. org/10.1136/archdischild-2011-300888 
O'Nions E, Wolke D, Johnson S, Kennedy E. Preterm birth: Educational and mental health outcomes. Clin Child Psychol Psychiatry. Copyright (C) 2021. DOI: 10.1177/13591045211006754

Ritchie, K., Bora, S., \& Woodward, L. J. (2015). Social development of children born very preterm : A systematic review. Developmental Medicine \& Child Neurology, 57(10), 899-918. https://doi.org/10.1111/ dmcn.12783

Ritchie, K., Bora, S., \& Woodward, L. J. (2018). Peer relationship outcomes of school-age children born very preterm. The Journal of Pediatrics, 201, 238-244. https://doi.org/10.1016/j.jpeds.2018.05.034

Simms, V., Gilmore, C., Cragg, L., Clayton, S., Marlow, N., \& Johnson, S. (2015). Nature and origins of mathematics difficulties in very preterm children: A different etiology than developmental dyscalculia. Pediatric Research, 77(2), 389-395. https://doi.org/10.1038/pr.2014.184

Smith, L. K., Draper, E. S., \& Field, D. (2014). Long-term outcome for the tiniest or most immature babies: Survival rates. Seminars in Fetal and Neonatal Medicine, 19(2), 72-77. https://doi.org/10.1016/j. siny.2013.11.002

Spittle, A., Orton, J., Anderson, P. J., Boyd, R., \& Doyle, L. W. (2015). Early developmental intervention programmes provided post hospital discharge to prevent motor and cognitive impairment in preterm infants. Cochrane Database of Systematic Reviews, 11, CD005495. https://doi.org/10.1002/14651858. CD005495.pub4

Twilhaar, E. S., Kieviet, J. F. De, Elburg, R. M. Van, \& Oosterlaan, J. (2018a). Academic trajectories of very preterm born children at school age. Archives of Disease in Childhood - Fetal and Neonatal Edition, 103(4), F322-F330. https://doi.org/10.1136/archdischild-2018-315028

Twilhaar, E. S., Wade, R. M., de Kieviet, J. F., van Goudoever, J. B., van Elburg, R. M., \& Oosterlaan, J. (2018b). Cognitive outcomes of children born extremely or very preterm since the 1990s and associated risk factors. JAMA Pediatrics, 172(4), 361. https://doi.org/10.1001/jamapediatrics.2017.5323

Upadhyaya, S., Sourander, A., Luntamo, T., Matinolli, H.-M., Chudal, R., Hinkka-Yli-Salomäki, S., Filatova, S., Cheslack-Postava, K., Sucksdorff, M., Gissler, M., Brown, A. S., \& Lehtonen, L. (2020). Preterm birth is associated with depression from childhood to early adulthood. Journal of the American Academy of Child \& Adolescent Psychiatry. Advance online Publication. https://doi.org/10.1016/j.jaac.2020.09.020

Van Lieshout, R. J., Boyle, M. H., Favotto, L., Krzeczkowski, J. E., Savoy, C., Saigal, S., \& Schmidt, L. A. (2018). Impact of extremely low-birth-weight status on risk and resilience for depression and anxiety in adulthood. Journal of Child Psychology and Psychiatry, 59(5), 596-603. https://doi.org/10.1111/ jcpp. 12826

Vinall, J., Miller, S. P., Synnes, A. R., \& Grunau, R. E. (2013). Parent behaviors moderate the relationship between neonatal pain and internalizing behaviors at 18 months corrected age in children born very prematurely. Pain, 154(9), 1831-1839. https://doi.org/10.1016/j.pain.2013.05.050

Vohr, B., McGowan, E., McKinley, L., Tucker, R., Keszler, L., \& Alksninis, B. (2017). Differential effects of the single-family room neonatal intensive care unit on 18- to 24-month bayley scores of preterm infants. The Journal of Pediatrics, 185, 42-48.e1. https://doi.org/10.1016/j.jpeds.2017.01.056 
O'Nions E, Wolke D, Johnson S, Kennedy E. Preterm birth: Educational and mental health outcomes. Clin Child Psychol Psychiatry. Copyright (C) 2021. DOI: 10.1177/13591045211006754

Volpe, J. J. (2009). Brain injury in premature infants: A complex amalgam of destructive and developmental disturbances. The Lancet Neurology, 8(1), 110-124. https://doi.org/10.1016/S1474-4422(08)70294-1

World Health Organization. (2020). Newborns: Reducing mortality. https://www.who.int/en/news-room/factsheets/detail/newborns-reducing-mortality

Wolke, D. (2018). Commentary : Preterm birth : High vulnerability and no resiliency? Reflections on van Lieshout et al. (2018). Journal of Child Psychology and Psychiatry, 11, 1201-1204. https://doi. org/10.1111/jcpp.12971

Wolke, D. (2019). Is social inequality in cognitive outcomes increased by preterm birth-related complications? JAMA Network Open, 2(5), e192902. https://doi.org/10.1001/jamanetworkopen.2019.2902

Wolke, D., Baumann, N., Strauss, V., Johnson, S., \& Marlow, N. (2015). Bullying of preterm children and emotional problems at school age: Cross-culturally invariant effects. The Journal of Pediatrics, 166(6), 1417-1422. https://doi.org/10.1016/j.jpeds.2015.02.055

Wolke, D., Jaekel, J., Hall, J., \& Baumann, N. (2013). Effects of sensitive parenting on the academic resilience of very preterm and very low birth weight adolescents. Journal of Adolescent Health, 53(5), 642- 647. https://doi.org/10.1016/j.jadohealth.2013.06.014

Wolke, D., Johnson, S., \& Mendonça, M. (2019). The life course consequences of very preterm birth. Annual Review of Developmental Psychology, 1(1), annurev-devpsych-121318-084804. https://doi.org/10.1146/ annurev-devpsych-121318-084804

Zeitlin, J., Manktelow, B. N., Piedvache, A., Cuttini, M., Boyle, E., van Heijst, A., Gadzinowski, J., Van Reempts, P., Huusom, L., Weber, T., Schmidt, S., Barros, H., Dillalo, D., Toome, L., Norman, M., Blondel, B., Bonet, M., Draper, E. S., \& Maier, R. F. (2016). Use of evidence based practices to improve survival without severe morbidity for very preterm infants: Results from the EPICE population based cohort. BMJ, 354, i2976. https://doi.org/10.1136/bmj.i2976 